\title{
Prevention and Therapy of COVID-19 via Exogenous Estrogen Treatment for Both Male and Female Patients; An Opinion Paper
}

\author{
Zsuzsanna Suba \\ National Institute of Oncology, Department of Molecular Pathology, Budapest, Hungary \\ Received, April 20, 2020; Revised, April 22, 2020; Accepted, April 22, 2020; Published, April 22, 2020
}

\begin{abstract}
The presented work summarizes the results of studies underlining the crucial role of estrogen receptor (ER) signaling in both innate and adaptive immune responses as well as in tissue repairing processes during respiratory virus infection. Experimental studies justify that among respiratory virus infected mice, a weaker ER signaling leads to increased morbidity and mortality in both males and females. In animal experiments, estrogen treatment silences the inflammatory reactions and decreases virus titers leading to improved survival rate; it seems to be an ideal prevention and therapy against COVID-19. We should overcome the widespread reluctance to estrogen therapy as we have a unique estrogen formula; conjugated estrogens, or conjugated equine estrogens available under the brand name of Premarin deriving from natural sources. Premarin can exert similar ER upregulative and gene repairing power like endogenous estrogen without any risk for adverse reactions. Premarin is capable of stopping the COVID-19 pandemic.
\end{abstract}

In December, 2019 a serious pneumonia emerged in Wuhan (China) and a novel coronavirus, designated as Severe Acute Respiratory Coronavirus 2 (SARS$\mathrm{CoV}-2)$ was identified as an etiological factor [1]. In February 27, 2020, more than 82000 cases infected with coronavirus were registered and 2800 cases with fatal outcome were reported. At that time, infected cases were reported in 49 countries, of which approximately $95 \%$ of infected patients and $97 \%$ of deaths were in China [2]. The virus genome was rapidly sequenced, which helped the development of diagnostic tests and the development of vaccination. Meanwhile, the data concerning the biology, epidemiology, and clinical characteristics of the SARS-CoV-2 infection were growing daily [3].

In the US, the first case of COVID-19 was identified in Washington State on January 20, 2020, while in just over 2 months more than 235000 cases have been identified overall in US [4]. By March 17, the epidemic had rapidly expanded from Washington, New York, and California to all 50 states. By April 2, in the US, more than 5000 fatal outcome associated with COVID-19 were registered. At the same time the US became the mostly affected country with the largest number of reported COVID-19 cases comprising about $20 \%$ of all reported infections out of more than 1 million globally identified cases.

The reported global mortality rate of COVID19 on April 2, 2020 was $4.7 \%$ but this varied widely by countries. Among the first 140904 cases diagnosed in the US, $1.7 \%$ died; however, the established case/fatality rate (CFR) may highly be influenced by the reliable estimation of the total number of identified cases [4]. In Italy, an extremely high value of CFR was registered: $10.8 \%$, while in Germany the lowest CFR value was established: $0.7 \%$.

According to early Chinese reports, women are less susceptible to COVID-19 and female patients exhibit a significantly lower mortality rate compared to males [1,5]. Later on, the global expansion of COVID-19 outbreak clearly revealed that SARS-CoV-2 seems to be infecting and killing much more men than women [6-9].

These epidemiological data are equivalent with the results of earlier studies reported on other coronavirus outbreaks included SARS-CoV and MERS-CoV (Middle East Respiratory Syndrome Corona Virus); among men, morbidity and fatality rates were markedly higher compared to women $[10,11]$. When patients aged 70 and above were examined, the advantage of lower morbidity and mortality disappeared among coronavirus infected women [12].

In contrast, reports on the epidemiology of influenza A virus (IAV) outbreaks and pandemics revealed that the severity and mortality of influenza are typically higher for women in their reproductive period than for age matched men $[13,14]$. These findings suggested inverse sex related differences in

Correspondent author: Prof. Dr. Zsuzsanna Suba, National Institute of Oncology, Department of Molecular Pathology, H-1122, Ráth György str. 7-9, Budapest, Hungary; Tel: 0036122486 00; Fax: 0036 122486 20; email: $\underline{\text { subazdr@gmail.com }}$ 
the outcome of IAV infection as compared with coronavirus induced diseases. The inverse sex dependant severity and outcome of IAV and corona virus associated respiratory infections were thoroughly investigated in both epidemiological and experimental studies [15]. Researchers arrived at a paradigm; either weaker immune response in males with androgen excess or robust immune response in females with estrogen excess could presumably promote unquenchable inflammatory immune response leading to fatal outcome [16].

Today, COVID-19 pandemic arrived at an emergency situation worldwide and medical efforts are helpless in restraining the global infection among people. Development of vaccination against an earlier unknown, aggressive virus takes several months or even years, while providing help for virus infected people with acute respiratory distress syndrome would be very urgent. Nowadays, there is no drug with appropriate official regulatory approval to treat the disease [17].

The presented work summarizes the results of studies underlining the crucial role of estrogen receptor (ER) signaling in both innate and adaptive immune responses as well as in tissue repairing processes during respiratory virus infection in both males and females. Since estrogen treatment in animal experiments, silences the inflammatory reactions and decreases virus titers leading to improved survival rate, it seems to be an ideal prevention and therapy against COVID-19. We should overcome the widespread reluctance to estrogen therapy as we have a unique estrogen formula; conjugated estrogens, or conjugated equine estrogens (Premarin) deriving from natural sources. Premarin can exert similar ER upregulative and gene repairing power like endogenous estrogens without any risk for adverse reactions. Premarin is capable of stopping the COVID-19 pandemic.

\section{Infection and mortality rates increase with advancing age}

The vast majority of Chinese cases with COVID-19 (87\%) were adults in ages 30 to 79 as it was reported by the China Center for Disease Control based on the data of 72,314 patients with diagnosed COVID19 infection until 11. February 2020 [2]. Young age seemed to be highly protective against the infection; $8.1 \%$ of diagnosed cases were in their twenties, $1.2 \%$ were teenagers, and $0.9 \%$ were 9 or younger children.

The severity of COVID-19 is age related. Of those patients treated at Central Hospital of Wuhan, about half of 109 COVID-19 patients (ages 22 to 94) developed ARDS reducing the oxygen supply to vital organs, and half of the ARDS affected patients died as compared with the $9 \%$ of patients who did not develop respiratory distress [18]. Patients developing ARDS had an average age of 61, while patients without ARDS were significantly younger having an average age of 49 .

In China, conspicuously increased age related mortality was observed among patients with COVID-19 [18]. China Center for Disease Control reported overall 2.3\% fatal cases out of COVID-19 patients. The death rate was conspicuously high; $14.8 \%$ among infected people aged 80 or older. The death rate was $1.3 \%$ in those aged 50 to 59 years, $0.4 \%$ among those 40 to 49 and $0.2 \%$ in people aged 10 to 39. China CDC reported on 549 COVID-19 infected cases among children and teenagers and only one had died out of them.

Analyzing the data of 4,226 COVID-19 cases from the US Centers for Disease Control (CDC), $31 \%$ was 65 years or older; $45 \%$ of them required hospitalization [19]. Mortality rates of people 85 years and older ranged between $10-27 \%$. Out of patients between 65 and 84 years, $3-11 \%$ had a fatal outcome. Among those between 55 and 64, less than $1 \%$, while in those 19 and younger $0 \%$ dyed. Although, severe disease and death from COVID19 infection may occur in patient of any age, $80 \%$ of deaths in U.S. were registered in those 65 years or older and the worst outcome was observed among people 85 years and older.

\section{Women are less susceptible to COVID-19 and exhibit a markedly low mortality rate compared to males}

Evaluation of the gender-related distribution among cases with COVID-19 revealed a higher susceptibility to the virus infection and a higher mortality rate of male patients as compared with females. These gender differences were observed among all age groups of adult patients [1,5].

In a retrospective single center study in Wuhan Jinyintan Hospital, epidemiological, demographic, clinical and radiological features of 99 confirmed cases with COVID-19 from Jan 1 to Jan 202020 were registered and the outcomes of diseases were followed up until Jan 25, 2020 [1]. The average age of patients with COVID-19 pneumonia was 55.5 years and a conspicuous male predominance was observed (67 men versus 32 women). Imaging examination showed bilateral pneumonia in $75 \%$ of patients. Acute respiratory distress syndrome 
(ARDS) developed in $11 \%$ of patients leading to multiple organ failure and fatal outcome.

The China Medical Treatment Expert Group for COVID-19 in Wuhan reported a 58\% predilection of male cases among 1099 patients suggesting an increased susceptibility to corona virus infection among men [5].

U.S. researchers reported that among hospitalized serious cases with COVID-19 there was a predominance of men [3]. Authors suggested that when the virus affect men harder than women, healthcare systems will see, test and control more men.

Chinese researchers established that the overall death rate among 44,672 confirmed cases with coronavirus infection was $2.3 \%$. At the same time, the death rate among male patients was significantly higher $(2.8 \%)$ compared to that of female cases $(1.7 \%)$ representing a $48.89 \%$ difference. Since the mortality rate from COVID-19 is nearly $50 \%$ higher in men than in women, researchers are looking for answers [18].

Scientists at Wuhan University reported the findings on nine pregnant women infected with CoV-19 [20]. High estrogen levels and increased ER signaling in pregnant women was not associated with severe disease, none of them developed virus pneumonia. In addition, none seemed to pass the virus to their babies; they all were scored at the top of the Apgar scale indicating an excellent newborn health.

Earlier, major coronavirus outbreaks such as Severe Acute Respiratory Syndrome (SARS) originated from China in 2003 and Middle East Respiratory Syndrome (MERS), first reported in Saudi Arabia in 2012, also killed more men than women [10]. Sex related differences in morbidity and mortality were less apparent in patients aged 70 and above [12], when women are in their late postmenopausal status. Epidemiological data deriving from SARS and MERS CoV epidemics indicated that the outcome of human corona virus infections is strongly sex-dependent suggesting the role of stronger protective estrogen signal in adult female patients compared to age matched males.

\section{Animal experiments justify a stronger protection of females against corona virus infection compared to males}

Results of animal experiments strongly indicated that male mice were more susceptible to SARS$\mathrm{CoV}$ infection as compared with females [21]. The male susceptibility to SARS virus infection increased with ageing; middle aged mice showed more pronounced gender-related differences in the severity of disease. Virus titers in males were highly elevated as compared with females, and a strong inflammatory immune response increased the risk for fatal outcome of the disease [22].

In male mice, gonadectomy or treatment with an anti-androgen compound (flutamide) did not affect the morbidity and mortality rates following lethal virus infection, suggesting that androgen deprivation do not influence the pathogenesis of SARS-CoV induced disease. Conversely, estrogen depletion by ovariectomy or treatment with estrogen receptor (ER) antagonist in SARS-CoV infected female mice dramatically increased both morbidity and mortality justifying the crucial role of estrogen activated ERs in life saving protection against respiratory virus [21].

In virus infected ovariectomized female mice, an $85 \%$ death rate was observed by day 8 , while only a $10-20 \%$ mortality rate was registered among virus infected controls with intact ovaries. In addition, female mice treated with ER antagonist (ICI 182780), were more susceptible to virus infection as compared with those treated with ER agonist. Estrogen loss in corona virus infected ovariectomized female mice mimicked the immense inflammatory response that was observed in more vulnerable males increasing disease severity and risk for dying [22].

In female mice with corona virus infection, the most prominent sex-specific protection was observed during their reproductive period associated with strong ER signaling. In contrast, young male and female animals exhibited an equal defense, while aged animals showed equally strong vulnerability in both sexes [21]. The available experimental and human epidemiological data equally justify that in adult female cases, stronger ER signaling may have a crucial role in the health protection against corona virus infection compared to males.

\section{Pre-existing chronic diseases associated with insulin resistant status aggravate the outcome of COVID-19 infection}

People with pre-existing diseases are more likely to get seriously ill from COVID-19, and men debilitated by chronic illnesses, such as chronic heart disease and type-2 diabetes exhibit a much higher mortality rate [23]. In China, researchers analyzed the data of 1,590 patients with laboratory confirmed COVID-19 infection. The correlations between pre-existing diseases and the risk of 
admission to intensive care unit or dying among coronavirus infected patients were studied.

The most frequent co-morbidities among COVID-19 infected patients were: cardiovascular diseases, type- 2 diabetes, chronic obstructive pulmonary disease, chronic kidney disease and cancer. The investigators established that 399 patients with one additional disease had a $79 \%$ greater chance for needing intensive care or a respirator assistance as well as for dying. In addition, 130 patients having two or more additional diseases exhibited 2.5 times higher risk for ARDS or dying [23].

The coronavirus infection show rapid spread in nursing homes. The coronavirus outbreak in a King County Washington nursing facility, sickened 129 people; 81 of 130 residents, 34 of 170 workers and 14 visitors, and killed 23 cases within two weeks [24]. The most common co-morbidities among residents were high blood pressure (69\%), coronary heart disease (57\%), kidney disease (43\%), diabetes $(37 \%)$ and obesity (33\%).

All comorbidities aggravating the outcome of COVID-19 infection are in strong correlation with insulin resistant states (metabolic syndrome, type-2 diabetes) in both men and women. Insulin resistance (type-2 diabetes, metabolic syndrome) always is associated with a deficient ER signaling in the background [25]. Type-2 diabetes strongly inhibits estrogen regulated innate and adaptive immune functions and alters patient's capacity to resolve inflammation and repair damaged tissue [26].

\section{Correlations between insulin resistance and defective ER signaling in the development of human diseases}

Insulin resistance (IR) is a defect of insulin assisted cellular glucose uptake. IR has a fundamental role in the development of human diseases and its progression equally predisposes both male and female patients to a variety of diseases including metabolic syndrome, type-2 diabetes and cardiovascular diseases [27]. From the beginning of the $20^{\text {th }}$ century, IR has been regarded as a strong cancer risk factor for several organs in both men and women [28]. The IR associated cellular malnourishment was the first among recognized pathological processes affecting detrimentally the genetic regulation of all cellular functions including DNA stabilization.

In premenopausal young women, insulin resistant states included metabolic syndrome and type-2 diabetes, show strong correlation with menstrual disorders and anovulatory infertility revealing a defective estrogen signaling in the background [29]. In postmenopausal women, a decreased estrogen synthesis is associated with insulin resistance, and accumulation of central adipose tissue; both of which are improved by menopausal hormone therapy. [30]. In conclusion, low estrogen level and/or defective estrogen signaling in women results in defects of glucose uptake and energy expenditure [25].

Among insulin resistant men with metabolic syndrome or type-2 diabetes, the defect of estrogen signaling in the background is not manifested by clinical symptoms. By contrast, inherited serious mutations of ESR1 gene of ERs or aromatase coding CYP19 gene in men may result in extreme defects of estrogen signaling leading to serious insulin resistance and its co-morbidities [31,32].

In 2007, estrogen deficiency coupled with insulin resistant states was exposed as a newly recognized risk factor for oral cancer (OC) in a Hungarian study [33]. In young girls and boys, OC incidence was extremely rare. Among adult men, OC incidence was increasing with ageing, while age matched women being in their reproductive period were strongly protected. Among aged people above 70 , OC incidence in males and females became equalized as OC incidence among postmenopausal women steeply increased with aging parallel with their estrogen loss. Later on, deficient estrogen signaling seemed to be a cancer risk factor for several organs including the female breasts $[34,35]$.

The similar demographic data of OC incidence and the severity of COVID-19 strongly suggest that in premenopausal women having healthy hormonal cycles, a strong estrogen signal is protective against both oral cancer and respiratory virus infection.

\section{Estrogen receptor signal regulates immune responses to respiratory viral infection in both men and women}

Ligand activated ERs are hubs of the network of genomic machinery in mammalians regulating both somatic and reproductive cellular functions [36]. Alterations in ER activation or in ER regulated transcriptional processes may induce strong compensatory actions, while an uncompensated deregulation of ER signaling leads to serious chronic diseases included cancer [37].

Estrogen activated estrogen receptors (ERs) as transcription factors regulate the development of immune cells and the pathways of innate and adaptive immune system [38]. Conversely, changes in androgen receptor (AR) signaling do not exhibit 
marked influences on inflammatory and reparative immune reactions [21]. Consequently, the stronger the upregulation of ER signaling in either male or female patients, the more effective is the response against respiratory viruses. Stronger immune responses in females are attributed to their stronger regulatory circuit of estrogen-ER-aromataseestrogen serving their immense roles in reproductive functions [37].

In the reproductive life period of women, estrogen levels are higher and ER signaling is much stronger compared to age matched men, consequently immune defense against respiratory viruses exhibits conspicuous sex differences [38]. In adult men, estrogen levels and ER signaling also are crucial for the maintenance of reproductive capacity and somatic health, while estrogen deficiency has severe consequences [39]. ERs have crucial role in the maintenance of glucose homeostasis; however, there are few documented human cases on strongly defective ER signaling in males [40]. The case of a male patient was reported with inherited mutations of both ER $\alpha$ alleles [31]. This patient exhibited ER resistance to estrogen inducing glucose intolerance, hyperinsulinemia, severe osteoporosis and premature serious cardiovascular disease providing evidences for the genome wide role of ER signaling in male physiology.

Both male and female ER $\alpha$ knockout mice exhibit insulin resistance, impaired glucose tolerance and obesity indicating the importance of ER signaling in the maintenance of glucose homeostasis in both sexes [41]. In ER $\alpha$ knockout mice, autoimmune nephritis, myeloid leukemia and Sjögren syndrome were diagnosed demonstrating that ERs have pivotal roles in the regulation of immune system [42-44]. These observations justify that the development of autoimmune diseases may be in correlation with a defect of ER signaling instead of its extreme upregulation.

The androgen excess and the predominant androgen receptor signal mistakenly suggest that in males, androgens may play a crucial role in both innate and adaptive immune responses instead of estrogens. Nevertheless, in male mice infected with a lethal dose of SARS-CoV, gonadectomy or antiandrogen treatment could not influence either morbidity or mortality, indicating that a lack of androgens did not affect immune responses. At the same time, sublethal SARS-CoV infection significantly reduced serum testosterone levels in male mice [21]. Rapid conversion of androgens to estrogens via increased aromatase expression may be an effort for silencing the cytokine storm of virus infected lungs in male mice, which leads to testosterone depletion.

In conclusion, there are no quite different molecular and cellular pathways for immune defense against respiratory virus infection in males and females, but rather a physiologically weaker estrogen signaling results in increased morbidity and mortality among men with pulmonary virus infection.

\section{The upregulative circuit of estrogen activated ERs and aromatase enzyme have crucial roles in immune responses to respiratory virus infection}

Experimental manipulation of ER signaling justified that either estrogen loss or a deletion of ERs may alter the function of both immune cells and other cell types participating in immune responses [38]. In conclusion, estrogen activated ERs have crucial roles in the regulation of immunologic processes in health and disease.

In respiratory virus infected lungs, three phases of immune responses may be observed [45]. In the first phase, innate immune cells initiate early antiviral responses and organize the adaptive responses. In the second phase, virus infected cells are killed and antiviral antibodies are synthesized. In the final phase, immune mediators repair the injured cells and tissues restoring the original structures.

In the initial phase of type 1 immune response to respiratory virus infection, an increased number and activation of innate lymphocytes and myeloid cells; neutrophil leukocytes, monocytes, alveolar macrophages and dendritic cells may be observed [15]. Estradiol in virus infected female mice, elevated neutrophil chemo attractants recruiting neutrophils into the lungs and they promote adaptive $\mathrm{T}$ cell responses [46]. Innate immune cells, monocytes, macrophages and neutrophils exhibit high ER expression suggesting a crucial role of estrogen signaling in their differentiation and proliferation $[47,48]$.

Estrogen activates ERs in accumulated monocytes, macrophages and neutrophils inducing the production of proinflammatory cytokines (IL12, TNF $\alpha$ ), and chemokine (CCL2). ER activation in lymphocytes induces type I and III interferon (IFN) production [49]. Proinflammatory cytokines and chemokines activate aromatase expression and promote the conversion of androgens to estrogens. Increased estrogen concentration and upregulative $\mathrm{ER} \alpha$ activation enhance type I and III IFN 
synthesis, which is important for decreasing the virus titer [15]. In females, plasmocytoid dendritic cells (pDCs) synthesized more type I IFN than in males, which inhibits the replication of viruses [50,51].

In the early phase of antiviral immune response, proinflammatory cytokine productions were equally high in both sexes, while in female mice, the abundant production of cytokines induced higher aromatase expression and estrogen synthesis than in males [21]. In females, at $72 \mathrm{~h}$ post infection, high estrogen concentration upregulated ER signaling, silenced the cytokine storm and eliminated the accumulated exsudate of inflammatory cells. At the same time, in males, the level of cytokines and chemokines remained high or even increased in the lungs leading to prolonged inflammatory response attributed to their low estrogen production and weak ER signaling [21]. These findings are consistent with the observation that in ovariectomized female mice, estrogen loss promotes excessive inflammatory immune responses to virus infection, while high dose estradiol replacement quenches the inflammatory reaction and promotes adaptive immunity [52].

Estrogen inhibited the replication of influenza virus in nasal epithelial cells and at the same time, upregulated ER signaling helping the preservation of cell integrity via gene modification and improving the metabolic functions [53].

Type 2 immune responses promote the resolution of immune reactions elicited by respiratory virus infection and work on the repair of injured tissues [54,55]. Estrogen activated ER $\alpha$ promotes type 2 responses of alveolar macrophages (AMs), innate lymphoid cells (ILC2s) and myeloid cells [56], whilst androgens and androgen receptor signal attenuate all type 2 responses [57]. Lung resident AMs are phagocytic cells capable of production of soluble mediators against viral infection. Moreover, AMs produce abundant IFN I for viral clearance, and their chemokine production recruits monocytes into the lung [58]. Inflammatory responses of human monocyte-derived macrophages were increased by estrogen, while decreased by testosterone exposure $[59,60]$.

In the resolution phase of viral infection, female sex and strong ER $\alpha$ signaling promote type 2 responses coupled with tissue repair, whilst AR activation may calm these restorative processes [15].

\section{Apparent health disparity of females in IAV epidemic}

Reports on the pandemic IAV infections in 1957 and 2009 reveal that the hospitalization and mortality rate of adult patients following viral infection was higher for women than for men, while the morbidity was higher among men $[13,15]$. In 2009 , among patients infected with H1N1 influenza virus, 168 cases were critically ill. Their mean age was 32.3 , and 113 were female $(67.3 \%)$. Overall mortality among critically ill patients was $14.3 \%$ [14]. These epidemiological data apparently contradict to all observations suggesting that female sex and strong ER signaling are protective against respiratory virus infection.

In a recent study, severity and outcomes of viral pneumonia caused by influenza and MERScoronavirus infections were compared. The mortality rate of patients with pneumonia was significantly higher (13.8\%) among cases with MERS-CoV infection as compared with influenza cases. These results indicate that coronavirus is more aggressive and induces more severe disease and worse outcome than influenza virus does [61].

IAV shows weaker infective capacity as compared with corona viruses; however it may induce widespread infection among adult men. Among women with good aptitude for upregulative ER signaling, IAV infection remains undiagnosed resulting in a lower incidence of influenza among women as compared with men. IAV selects women with more or less compromised immune system attributed to their inherited or acquired weakness of ER signaling. In the smaller population of IAV infected women, the lower expression of estrogen regulated genes results in male-like unquenchable inflammatory reaction in the lung leading to increased severity and mortality of the disease.

In conclusion, increased morbidity and mortality among a smaller female population with IAV infection may be attributed to the weak infective capacity of IAV and to the weak ER signaling of selectively infected female population with insufficient estrogen protection. In contrast, SARS-CoV-2 is a highly aggressive corona virus evoking higher morbidity and mortality among men as compared with women [5]. Highly infective corona viruses are capable of causing widespread disease among both male and female populations. Since SARS-CoV-2 may similarly attack female populations having either good or weak ER 
signaling, the demographic data of COVID-19 outbreak equivocally show that taken as a whole, women have markedly better defense mechanisms against COVID-19 infection as compared with men.

In animal experiments, sex differences in susceptibility and immunity to influenza A virus (IAV) were investigated on mice [52]. Virus titers in the lung were similar in both sexes; however, a higher induction of inflammatory cytokines and higher mortality rates were observed among ill female mice. Manipulations of androgen hormone concentrations in male mice did not significantly affect immune responses to respiratory virus. In contrast, high doses of estradiol in females lowered more than 10-fold the induction of cytokines and chemokines in the lung and increased the survival rates compared to estrogen deficient female mice. In IAV infected female mice, the protective effects of high dose estradiol against cytokine storm, morbidity and mortality were mediated by the upregulation of ER $\alpha$ signaling.

\section{An 80 year period of synthetic estrogen use in medical practice mistakenly induced a fear of even endogenous estrogens}

From the early 1940s, various synthetic estrogens were developed for many purposes, such as the treatment of miscarriage and menopausal symptoms and for oral contraception [62].

A nonsteroidal synthetic estrogen diethylstilbestrol (DES) was used for pregnant women to prevent miscarriage. DES treatment proved to be ineffective in miscarriage prevention; however it caused adverse effects on both pregnancy and fetal development [63]. Moreover, DES exposure during pregnancy induced increased breast cancer risk in both mothers [64] and daughters [65]. Clinical experiences with synthetic DES exposure mistakenly suggested that in pregnant women, even an increased endogenous estrogen level may induce developmental anomalies in fetuses and elevates the risk for breast cancer in both mothers and daughters.

Oral contraceptives (OCs) were developed in the early 1960 s comprising predominantly a steroidal estrogenic compound ethinylestradiol (EE), and later, a synthetic 17-beta estradiol (SE2) also was used as an OC component [66]. OCs comprising low doses of synthetic estrogens, apparently worked well in women, however, in certain cases they evoked unforeseeable complications, such as venous thromboembolism, stroke and myocardial infarct suggesting severe clotting disorders $[67,68]$. Moreover, correlations between OC use and a moderately increased overall breast cancer risk were reported [69], while the incidence of ER negative and triple negative breast cancers was significantly increased in OC users $[70,71]$.

The increased prevalence of poorly differentiated, ER negative breast cancers among OC users, strongly suggested that synthetic estrogens rather deregulate ER activation instead of an excessive stimulation [72]. Despite the well known risk for severe complications in OC users, internists, endocrinologists and gynecologists prescribe OCs for healthy women erroneously believing that increased doses of even endogenous estrogens may cause insulin resistance, thromboembolic events and increased breast cancer risk.

In rat models of human breast cancer, exposure to excessive synthetic estrogens included SE2 promoted mammary tumor genesis during pregnancy [62]. In rats, all synthetic estrogens, even SE2 induced persistent changes in estrogen regulated genes, in DNA methylation and histone modification [62]. These observations mistakenly suggested that both synthetic and natural estrogens are capable of disturbing the development and physiology of female breasts.

In reality, all examined synthetic estrogens work as weak antiestrogens even when administered in low doses as they inhibit the unliganded activation of ERs [73]. The estrogenlike effects of synthetic estrogens may be attributed to the compensatory upregulation of liganded ER activation, while the deregulation of ERs leads to toxic complications and increased breast cancer risk, ER negative ones in particular [74].

For menopausal hormone therapy (MHT), both synthetic estrogens and conjugated equine estrogens (CEEs) with natural origin were introduced [75]. In the early MHT studies, all hormones were designated simply as exogenous estrogens without sharp distinction between natural and synthetic estrogen formulas. In postmenopausal women, the use of estrogens with different origin and even their combinations with synthetic progestogens resulted in a chaos of quite controversial clinical experiences concerning the risks for thromboembolic complications and breast cancer [74]. Wide spread use of MHT has provided an expanding clinical database mistakenly suggesting that even endogenous estrogen hormone may have crucial role in the development of both coronary heart disease and breast cancer. 
Retrospective analysis of the results of MHT studies revealed that the use of CEE alone (Premarin, Pfizer), deriving from pregnant horse urine, is highly beneficial for women's health $[74,76]$. Premarin treatment proved to be protective for the prevention of thromboembolism and cardiovascular disease [77], dyslipidemia [78], and bone loss [79]. In 2004, the Women's Health Initiative (WHI) Hormone Replacement Therapy (HRT) trial conducted on women without a uterus, found a significantly lower risk for breast cancer among Premarin treated cases compared to untreated controls [80]. In 2009, Ragaz et al. reported the protective effect of Premarin alone and increased breast cancer hazards with progestin after reviewing and re-evaluating the data of earlier WHI Hormone Replacement Therapy (HRT) trials. Premarin alone improved all aspects of women's health in addition to a significant decrease in breast cancer risk [81].

In 2019, in San Antonio Breast Cancer Symposium, WHI investigators presented an update on breast cancer findings from an earlier conducted WHI randomized controlled trial [82]. After more than 19 years, the follow up of postmenopausal women treated with Premarin alone, resulted in significant reductions in breast cancer incidence (23\%) and breast cancer associated mortality $(44 \%)$.

The long term benefit of Premarin use alone for women's health may be unique and may not be kept as equal to the effects of other (synthetic) estrogen formulas. After 19 years, the maintenance of advantageous anticancer effects of Premarin treatment may reflect its capacity for long term DNA repair via activating mutations justifying that it works through the same mechanisms like endogenous estrogen does [83].

\section{We have an effective medicament against COVID-19: Premarin}

Epidemiological and experimental data strongly indicate that estrogen activated ERs drive the successful immune protection against respiratory virus infections included both corona and influenza viruses. Weakness in ER signaling results in an excessive inflammatory response and respiratory distress in both males and females, while estrogen treatment upregulates the estrogenER-aromatase-estrogen circuit promoting the decrease of virus titer, the alleviation of inflammation, and the restoration of destructed tissues.
Out of available estrogen preparations, only Premarin can induce beneficial effects in human practice without adverse reactions suggesting that it exhibits similar DNA repairing and genome stabilizer effects like endogenous estrogen. Premarin treatment may prevent respiratory virus infections in susceptible people. Premarin may achieve dramatic improvement in patients suffering of acute respiratory distress syndrome; however, the result is not prompt as estrogen induced gene expression and new protein synthesis takes at least $24 \mathrm{~h}$.

\section{CONFLICT OF INTEREST:}

The author declares no conflict of interest, financial or otherwise.

\section{REFERENCES}

[1] Chen N, Zhou M, Dong X, et al. Epidemiological and clinical characteristics of 99 cases of 2019 novel coronavirus pneumonia in Wuhan, China: a descriptive study. Lancet. 2020; 395: 507-513.

[2] $\mathrm{Wu} \mathrm{Z,} \mathrm{McGoogan} \mathrm{JM.} \mathrm{Characteristics} \mathrm{of} \mathrm{and}$ important lessons from the coronavirus disease 2019 (COVID-19) outbreak in China: summary of a report of 72314 cases from the Chinese Center for Disease Control and Prevention. JAMA. February 24, 2020. doi:10.1001/jama.2020.2648

[3] del Rio C, Malani PN. COVID-19-New Insights on a Rapidly Changing Epidemic. JAMA. Published online February 28, 2020. doi:10.1001/jama.2020.3072

[4] Omer SB, Malani P, del Rio C. The COVID-19 Pandemic in the USA Clinical Update. JAMA. Published online April 6, 2020. doi:10.1001/jama.2020.5788

[5] Guan WJ, Ni ZY, Hu Y, Liang WH, Ou CQ, He JX, et al.; China Medical Treatment Expert Group for Covid-19. Clinical Characteristics of Coronavirus Disease 2019 in China. N Engl J Med. 2020 Feb 28:NEJMoa2002032. doi: 10.1056/NEJMoa2002032.

[6] EDITORS' PICK Forbes Healthcare. Sex Does Matter When It Comes To Coronavirus. Feb 22, 2020,08:16pm. By Nina Shapiro Contributor.

[7] www.statnews.com. HEALTH. Who is getting sick and how sick? A breakdown of coronavirus risk by demographic factors. By Sharon Begley March 3, 2020.

[8] The Wall Street Journal: SCIENCE. Coronavirus Seems to Be Infecting and Killing More Men Than Women. April 2, 2020 5:30 am. By Katie Camero.

[9] New York Times HEALTH. In N.Y.C. the Coronavirus Is Killing Men at Twice the Rate of Women. By Roni Caryn Rabin April 7, 2020 
[10] Karlberg J, Chong DS, Lai WY. Do men have a higher case fatality rate of severe acute respiratory syndrome than women do? Am J Epidemiol. 2004; 159: 229-231.

[11] Leong HN, Earnest A, Lim HH, Chin CF, Tan C, Puhaindran ME, Tan A, Chen MI, Leo YS. SARS in Singapore--predictors of disease severity. Ann Acad Med Singapore. 2006; 35: 326-331.

[12] Shaw AC, Goldstein DR, Montgomery RR. Agedependent dysregulation of innate immunity. Nature Rev Immunol. 2013; 13: 875-887.

[13] Klein SL, Hodgson A, Robinson DP. Mechanisms of sex disparities in influenza pathogenesis. J Leukoc Biol. 2012; 92(1): 67-73.

[14] Kumar AD, Zarychanski R, Pinto R, et al, Deborah J, Cook DJ, Marshall J, et al. Critically ill patients with 2009 influenza $\mathrm{A}(\mathrm{H} 1 \mathrm{~N} 1)$ infection in Canada JAMA. 2009; 302(17):1872-1879.

[15] Kadel S, Kovats S. Sex Hormones Regulate Innate Immune Cells and Promote Sex Differences in Respiratory Virus Infection. Front Immunol. 2018; 9: 1653.

[16] vom Steeg LG, Klein SL. SeXX matters in infectious disease pathogenesis. PLoS Pathog 2016; 12(2):e1005374.10.1371/journal.ppat.1005374

[17] Rabby MII. Current Drugs with Potential for Treatment of COVID-19: A Literature Review. J Pharm Pharm Sci. 2020; 23(1): 58-64. doi: 10.18433/jpps31002.

[18] China CDC Weekly: Vital Surveillances: The Epidemiological Characteristics of an Outbreak of 2019 Novel Coronavirus Diseases (COVID-19) China, 2020. The Novel Coronavirus Pneumonia Emergency Response Epidemiology. 2020; 2(8): 113-122.

[19] Severe Outcomes Among Patients with Coronavirus Disease 2019 (COVID-19) - United States, February 12-March 16, 2020. MMWR Morb Mortal Wkly Rep 2020; 69: 343-346.

[20] Chen H, Guo J, Wang C, et al. Clinical characteristics and intrauterine vertical transmission potential of COVID-19 infection in nine pregnant women. Lancet. Published February 12, 2020. doi:10.1016/S0140-6736(20)30360-3

[21] Channappanavar R, Fett C, Mack M, Eyck PPT, Meyerholz DK, Perlman S. Sex-Based Differences in Susceptibility to Severe Acute Respiratory Syndrome Coronavirus Infection. J Immunol, 2017; 198 (10), 4046-4053.

[22] Channappanavar R, Fehr AR, Vijay R, Mack M, Zhao J, Meyerholz DK, Perlman S. Dysregulated Type I Interferon and Inflammatory MonocyteMacrophage Responses Cause Lethal Pneumonia in SARS-CoV-Infected Mice. Cell Host Microbe. 2016; 19: 181-193.

[23] Guan WJ, Liang WH, Zhao Y, Liang HR, Chen ZS, Li YM, et al. Comorbidity and its impact on 1,590 patients with COVID-19 in China: A Nationwide
Analysis. medRxiv. The Preprint Server for Health Sciences. www.medrxiv.org. Febr. 27, 2020

[24] McMichael TM, Clark S, Pogosjans S, Kay M, Lewis J, Baer A, et al. COVID-19 in a Long-Term Care Facility - King County, Washington, February 27March 9, 2020. Weekly / March 26, 2020 / 69(12);339-342.

[25] Suba Z. Low estrogen exposure and/or defective estrogen signaling induces disturbances in glucose uptake and energy expenditure. J Diabet Metab 2013; 4: 272-81.

[26] Hulme KD, Gallo LA, Short KR. Influenza Virus and Glycemic Variability in Diabetes: A Killer Combination? Front Microbiol. 2017; 8: 861.

[27] Reaven GM. Banting lecture 1988 Role of insulin resistance in human disease. Diabetes. 1988; 37(12): 1595-607.

[28] Bloomgarden ZT. Second World Congress on the Insulin Resistance Syndrome Mediators pediatric insulin resistance the polycystic ovary syndrome and malignancy. Diab Care. 2005; 28(8 ): 1821-30.

[29] Suba Z. Diverse pathomechanisms leading to the breakdown of cellular estrogen surveillance and breast cancer development: new therapeutic strategies. Drug Des Devel Ther. 2014; 8: 13811390.

[30] Mauvais-Jarvis F, Manson JE, Stevenson JC, Fonseca VA. Menopausal Hormone Therapy and Type 2 Diabetes Prevention: Evidence, Mechanisms, and Clinical Implications. Endocr Rev. 2017; 38(3): 173-188.

[31] Smith, E.P., et al. Estrogen resistance caused by a mutation in the estrogen-receptor gene in a man. $\mathrm{N}$ Engl J Med 1994; 331, 1056-1061.

[32] Morishima, A., Grumbach, M.M., Simpson, E.R., Fisher, C., Qin, K. Aromatase deficiency in male and female siblings caused by a novel mutation and the physiological role of estrogens. J Clin Endocrinol Metab 1995; 80(12), 3689-3698.

[33] Suba, Zs. Gender-related hormonal risk factors for oral cancer. Pathol Oncol Res 2007; 13, 195-202.

[34] Suba Zs: Carcinogenesis theory based on estrogen deficiency. [In Humgarian]. Orvosi Hetilap 2009; 150:1155-1166.

[35] Suba Z. Circulatory estrogen level protects against breast cancer in obese women. Recent Pat Anticancer Drug Discov 2013; 8(2): 154-67.

[36] Maggi A. Liganded and unliganded activation of estrogen receptor and hormone replacement therapies. Biochim Biophys Acta 2011; 1812(8): 1054-1060.

[37] Suba Z. DNA stabilization by the upregulation of estrogen signaling in BRCA gene mutation carriers. Drug Des Devel Ther 2015; 9: 2663-75.

[38] Kovats S. Estrogen Receptors Regulate Innate Immune Cells and Signaling Pathways. Cell Immunol, 2015; 294 (2), 63-9. 
[39] Vanderschueren D, Bouillon R. Estrogen Deficiency in Men Is a Challenge for Both the Hypothalamus and Pituitary. J Clin Endocrin Metab 85(9); 3024-3026.

[40] Barros, R.P., Machado, U.F., Gustafsson, J.A. Estrogen receptors: new players in diabetes mellitus. Trends Mol Med 2006; 12(9), 425-431 (2006).

[41] Heine PA, Taylor JA, Iwamoto GA, Lubahn DB, Cooke PS. Increased adipose tissue in male and female estrogen receptor- $\alpha$ knockout mice. Proc Natl Acad Sci USA 2000; 97: 12729-12734.

[42] Shim G.J. et al. Autoimmune glomerulonephritis with spontaneous formation of splenic germinal centers in mice lacking the estrogen receptor $\alpha$ gene. Proc Natl Acad Sci USA 2004; 101: 1720-1724.

[43] Shim G.J. et al. Disruption of the estrogen receptor $\beta$ gene in mice causes myeloproliferative disease resembling chronic myeloid leukemia with lymphoid blast crisis. Proc Natl Acad Sci USA 2003; 100: 6694-6699.

[44] Shim G.J. et al. Aromatase-deficient mice spontaneously develop a lymphoproliferative autoimmune disease resembling Sjogren's syndrome. Proc Natl Acad Sci USA 2004; 101: 12628-12633.

[45] Yoo JK, Kim TS, Hufford MM, Braciale TJ. Viral infection of the lung: host response and sequelae. $\mathrm{J}$ Allergy Clin Immunol 2013; 132(6):1263-76.

[46] Robinson DP, Hall OJ, Nilles TL, Bream JH, Klein SL. 17beta-estradiol protects females against influenza by recruiting neutrophils and increasing virus-specific CD8 $\mathrm{T}$ cell responses in the lungs. J Virol 2014; 88(9): 4711-20.

[47] Murphy AJ, Guyre PM, Wira CR, Pioli PA. Estradiol regulates expression of estrogen receptor ERalpha46 in human macrophages. PLoS One 2009; 4(5):e5539.10.1371.

[48] Igarashi H, Kouro T, Yokota T, Comp PC, Kincade PW. Age and stage dependency of estrogen receptor expression by lymphocyte precursors. Proc Natl Acad Sci USA 2001; 98(26):15131-6.

[49] Newton AH, Cardani A, Braciale TJ. The host immune response in respiratory virus infection: balancing virus clearance and immunopathology. Semin Immunopathol 2016; 38(4): 471-82.

[50] Laffont S, Rouquie N, Azar P, Seillet C, Plumas J, Aspord C, et al. X-Chromosome complement and estrogen receptor signaling independently contribute to the enhanced TLR7-mediated IFN-alpha production of plasmacytoid dendritic cells from women. J Immunol 2014; 193(11): 5444-52.

[51] Seillet C, Laffont S, Tremollieres F, Rouquie N, Ribot C, Arnal JF, et al. The TLR-mediated response of plasmacytoid dendritic cells is positively regulated by estradiol in vivo through cell-intrinsic estrogen receptor alpha signaling. Blood 2012; 119(2): 45464.

[52] Robinson DP, Lorenzo ME, Jian W, Klein SL. Elevated 17beta-estradiol protects females from influenza A virus pathogenesis by suppressing inflammatory responses. PLoS Pathog 2011; 7(7):e1002149.10.1371.

[53] Peretz J, Pekosz A, Lane AP, Klein SL. Estrogenic compounds reduce influenza $\mathrm{A}$ virus replication in primary human nasal epithelial cells derived from female, but not male donors. Am J Physiol Lung Cell Mol Physiol. 2016; 310: L415-425.

[54] Gorski SA, Hufford MM, Braciale TJ. Recent insights into pulmonary repair following virusinduced inflammation of the respiratory tract. Curr Opin Virol 2012; 2(3): 233-41.

[55] Guo XJ, Thomas PG. New fronts emerge in the influenza cytokine storm. Semin Immunopathol 2017; 39(5): 541-50.

[56] Keselman A, Fang X, White PB, Heller NM. Estrogen signaling contributes to sex differences in macrophage polarization during asthma. J Immunol 2017; 199(5): 1573-83.

[57] Laffont S, Blanquart E, Guery JC. Sex differences in asthma: a key role of androgen-signaling in group 2 innate lymphoid cells. Front Immunol 2017; 8: 1069.

[58] Goritzka M, Makris S, Kausar F, Durant LR, Pereira C, Kumagai Y, et al. Alveolar macrophage-derived type I interferons orchestrate innate immunity to RSV through recruitment of antiviral monocytes. J Exp Med 2015; 212(5): 699-714.

[59] Rettew JA, Huet-Hudson YM, Marriott I. Testosterone reduces macrophage expression in the mouse of toll-like receptor 4, a trigger for inflammation and innate immunity. Biol Reprod 2008; 78(3): 432-7.

[60] Calippe B, Douin-Echinard V, Laffargue M, Laurell H, Rana-Poussine V, Pipy B, et al. Chronic estradiol administration in vivo promotes the proinflammatory response of macrophages to TLR4 activation: involvement of the phosphatidylinositol 3-kinase pathway. J Immunol 2008; 180(12): 7980-8.

[61] Al-Baadani AM, Elzein FE, Alhemyadi SA, Khan OA, Albenmousa AH Idrees MM. Characteristics and outcome of viral pneumonia caused by influenza and Middle East respiratory syndrome-coronavirus infections: A 4-year experience from a tertiary care center. Ann Thorac Med. 2019; 14(3): 179-185.

[62] Hilakivi-Clarke L, de Assis S, Warri A. Exposures to Synthetic Estrogens at Different Times During the Life, and Their Effect on Breast Cancer Risk. J Mammary Gland Biol Neoplasia. 2013; 18(1): 2542.

[63] Hoover RN, Hyer M, Pfeiffer RM, et al. Adverse health outcomes in women exposed in utero to diethylstilbestrol. N Engl J Med. 2011; 365: 13041314.

[64] Colton T, Greenberg R, Noller K, et al. Breast cancer in mothers prescribed diethylstilbestrol in pregnancy. JAMA. 1993; 269: 2096-2100.

[65] Palmer JR, Wise LA, Hatch EE, et al. Prenatal diethylstilbestrol exposure and risk of breast cancer. 
Cancer Epidemiol Biomarkers Prev. 2006; 15: 15091514.

[66] Coelingh-Bennink HJ, Verhoeven C, Dutman AE, Thijssen J. The use of high-dose estrogens for the treatment of breast cancer. Maturitas 2017; 95: 11-23.

[67] Lidegaard $\varnothing$, Løkkegaard E, Jensen A, Skovlund $\mathrm{CW}$, Keiding $\mathrm{N}$, et al. Thrombotic stroke and myocardial infarction with hormonal contraception. N Engl J Med 2012; 366: 2257-66.

[68] Petitti DB. Hormonal contraceptives and arterial thrombosis--not risk-free but safe enough. N Engl J Med 2012; 366: 2316.

[69] Brohet RM, Goldgar DE, Easton DF, Antoniou AC, Chang-Claude $\mathrm{J}$ et al. Oral Contraceptives and Breast Cancer Risk in the International BRCA1/2 Carrier Cohort Study: A Report From EMBRACE, GENEPSO, GEO-HEBON, and the IBCCS Collaborating Group. J Clin Oncol 2007; 25(25): 3831-36.

[70] Ma H, Wang Y, Sullivan-Halley J, Weiss L, Marchbanks PA, Spirtas R. Use of four biomarkers to evaluate the risk of breast cancer subtypes in the Women's Contraceptive and Reproductive Experiences Study. Cancer Res 2010; 70(2): 575-87.

[71] Dolle JM, Daling JR, White E, Brinton LA, Doody DR, Porter PL, et al. Risk factors for triple-negative breast cancer in women under the age of 45 years. Cancer Epidemiol Biomark Prev 2009; 18(4): 115766.

[72] Suba Z. Triple-negative breast cancer risk in women is defined by the defect of estrogen signaling: preventive and therapeutic implications. Onco Targets Ther 2014; 7: 147-64.

[73] Suba, Z. Amplified crosstalk between estrogen binding and GFR signaling mediated pathways of ER activation drives responses in tumors treated with endocrine disruptors. Recent Pat Anticancer Drug Discov 2018; 13(4), 428-444.

[74] Suba Z. Synthetic Estrogens Deregulate Estrogen Receptors Inducing Thromboembolic Complications and Cancer. In: Topics in Anti-Cancer Research. Vol. 8. Eds: Atta-ur-Rahman and Khurshid Zaman. Bentham Science Publishers 2019, Chapter 2, pp. 4473. DOI:10.2174/9789811404382119080005
[75] Stefanick ML. Estrogens and progestins: Background and history, trends in use, and guidelines and regimens approved by the US Food and Drug Administration. Am J Med 2005; 118(Suppl. 12B): 6473.

[76] Eurekalert! Is Premarin alone the key to successful menopausal hormone therapy? Z. Suba. Bentham Science Publishers. News Release 2-Febr-2020

[77] Stampfer MJ, Willett WC, Colditz GA, Rosner B, Speizer FE, Hennekens CH. A prospective study of postmenopausal estrogen therapy and coronary heart disease. N Engl J Med 1985; 313(17): 1044-9.

[78] Effects of estrogen or estrogen/progestin regimens on heart disease risk factors in postmenopausal women. The Postmenopausal Estrogen/Progestin Interventions (PEPI) Trial. JAMA 1995; 273(3): 199208.

[79] Osteoporosis. NIH Consens Dev Conf Consens Statement Online 1984 Apr 2-4 [cited year month day]. 5(3): 1-6.

[80] Anderson GL, Limacher M, Assaf AR, et al. Effects of conjugated equine estrogen in postmenopausal women with hysterectomy: The Women's Health Initiative randomized controlled trial. JAMA 2004; 291(14): 1701-12.

[81] Ragaz, J. Budlovsky J, Le N, Spinelli J. Protective effect of Estrogens alone and Increased Breast Cancer Hazards with Progestin. The 2009 Review of the Women's Health Initiative (WHI) Hormone Replacement Therapy (HRT) trials. American Association for Cancer Research, 2009. Presentation to the International San Antonio Breast Cancer Symposium, Dec 2009.

[82] Chlebowski RT, Anderson GL, Aragaki AK, Manson JE, Stefanick M, Pan K, et al. Long term influence of estrogen plus progestin and estrogen alone use on breast cancer incidence: The Women's Health Initiative randomized trials. San Antonio Breast Cancer Symposium. Abstracts Home Print Page. December 13, 2019, 9:30.

[83] Suba Z. Activating mutations of ESR1, BRCA1 and CYP19 aromatase genes confer tumor response in breast cancers treated with antiestrogens. Recent Pat Anticancer Drug Discov 2017; 12(2): 136-47. 